\title{
Application of artificial neural networks in the study of Mozzarella cheese salting
}

\author{
Talita Fogaça de OLIVEIRA ${ }^{1}$, Marco Aurélio Jeanegitz CLEMENTE ${ }^{1}$, Diego GALVAN ${ }^{1}$, Gustavo FIX ${ }^{1}$, \\ Ana Carolina Gomes MANTOVANI ${ }^{2}$, Ivanira MOREIRA ${ }^{1}$, Avacir Casanova ANDRELLO ${ }^{2}$, Karina Benassi ANGILELLI', \\ Dionísio BORSATO ${ }^{1 *}$ (D)
}

\begin{abstract}
A highly efficient tool that has stood out in data processing and treatment is Artificial Neural Networks (ANNs). Self-organized maps (SOM), which is a type of ANNs, are easy-to-view computational models that simulate information processing and knowledge acquisition. Applying this tool, we analyzed the behavior of the film formed on the mozzarella cheese surface when subjected to salting by immersion. In order to reduce the amount of $\mathrm{NaCl}$ in the food, $\mathrm{KCl}$ was used as a partial substitute in adequate amounts, without causing sensory changes in the cheese. The diffusion of salts in the brine is caused by the transfer of sodium and potassium ions, induced by concentration gradient of these salts inside and outside the food. The application of artificial neural networks proved to be an effective tool in the evaluation of the influence of the film on the diffusion process of $\mathrm{Na}^{+}$and $\mathrm{K}^{+}$ions, in the mozzarella cheese salting.
\end{abstract}

Keywords: self-organized maps; salts diffusion; static brine; dynamic brine.

Practical Application: Simulation of cheese salting processes providing interesting information for food industries.

\section{Introduction}

Since in the most diverse areas of science the amount of information produced is large, the extraction of information from the results of an experiment can become very difficult without using any data processing tool (Cremasco et al., 2016). For this reason, there is a need for highly efficient methods and applications to treat the results. A tool that has been shown to be suitable for treatments, in data that have nonlinear behaviors, are the Artificial Neural Networks (ANNs) (Borsato et al., 2011; Bittar et al., 2018).

There are several types of neural networks, and among them the self-organizing maps (SOM) stands out. This tool is able to order multivariate data for similarities, turning a standard incident input of arbitrary size, in an uni or bidimensional discrete map (Haykin, 2001). SOM performs this transformation in a topologically ordered manner, based on an unsupervised learning algorithm (Cremasco et al., 2016; Mattos et al., 2019).

In the last decades this tool has been gaining space in problems solving in different areas as in the investigation of the relative viscosity of multi-walled carbon nanotube (Maddah et al., 2018), prediction of chemical elements of the periodic table (Lemes \& Dal Pino, 2011) and waterlogging risk assessment (Lai et al., 2017). Cremasco et al. (2019) studied the application of artificial neural networks, SOM type, for the diffusion of inorganic ions in quail egg.

The phenomenon of salts diffusion leads to a balance through the solutes transfer that is induced by the difference in concentrations of salts located inside the food and in the brine (Gómez Salazar et al., 2015). Industrialized foods, such as Mozzarella cheese, are subjected to the salting process by immersion, in which the salt spreads in the solid by mass diffusion mechanisms (Albarracín et al., 2011; Guinee, 2004).

During the salting process, a film forms on the surface of the solid and acts as an ion entrance barrier, which can be expressed numerically by the mass Biot number (Angilelli et al., 2015; Schwartzberg \& Chao, 1982). According to Bordin et al. (2019) the higher the value of this parameter, the lower the influence of the formed film and the faster is the diffusion of salts into the food, reducing the salting time.

Cheeses make a significant contribution to sodium consumption which, when ingested in excess, can cause arterial hypertension (Rodrigues et al., 2015). Thus, in order to reduce the amount of sodium, potassium chloride has been used as a partial substitute up to $30 \%$, since when added in adequate amounts it does not cause sensory changes in foods (Bordin et al., 2019; Horita et al., 2014; Rodrigues et al., 2015).

The objective of this work was to apply the methodology of Artificial Neural Networks (ANN), Self-Organizing Maps (SOM) type, to identify and investigate the behavior of inorganic components in samples of Mozzarella cheese, submitted to the salting process in brines, in the static and agitated system.

\section{Materials and methods}

\subsection{Mozzarella cheese and brine}

The samples of mozzarella cheese used were produced according to Kosikowski (1978) and Furtado (1991). It was 
used pasteurized bovine milk, added citric acid and calcium chloride and then heated until $32^{\circ} \mathrm{C}$, with subsequent addition of liquid rennet previously diluted in water. After 40 minutes the formed mass was cut into homogeneous pieces and heated up to $43^{\circ} \mathrm{C}$ with slow stirring. The mass of the released serum was separated and this liquid was heated up to $85^{\circ} \mathrm{C}$. The pieces of the dough were separated into filaments and then shaped into standardized beakers.

A solution containing $15 \mathrm{~L}$ of brine with $5 \%(\mathrm{w} / \mathrm{v})$ salts was prepared. The salt composition was divided into $30 \% \mathrm{KCl}$ and $70 \% \mathrm{NaCl}$, according to Borsato et al. (2012). To ensure a constant salt concentration during the salting process, a volume approximately 30 times greater than the cheese samples was used. Because the mozzarella cheese was denser than the brine, the samples were arranged in a holder composed of nylon wires, all submerged. The diffusion processes were performed in stirred and dynamic brine, the latter with a solution flow of $520 \mathrm{Lh}^{-1}$, at a constant temperature of $20^{\circ} \mathrm{C}\left( \pm 1{ }^{\circ} \mathrm{C}\right)$ according to Bordin et al. (2019).

\subsection{Sampling and determination of moisture}

The cheeses were completely immersed in the static and dynamic brine and then collected at various time intervals until reaching $62 \mathrm{~h}$ and $50 \mathrm{~h}$ of immersion, respectively. At set time intervals $(0,0.25,0.75,1.0,2.5,6.5,7.5,9.5,10.5,11.5,17.5,19.0$, $29.0,36.0,40.0,50.0$ and $62.0 \mathrm{~h}$.) the samples were collected and measured according to Borsato et al. (2012) and the moisture determined after storage in stove at $105^{\circ} \mathrm{C}$ (Association of Official Analytical Chemists, 1994; Bordin et al., 2019).

\subsection{Determination of sodium and potassium}

The concentration of sodium and potassium ions in mozzarella cheese samples was measured according to Bordin et al. (2019) with modifications, using the Micronal photometer, model B-462, with air pressure of $0.8 \mathrm{kgf} \mathrm{cm}^{-2}$ and $1.5 \mathrm{kgf} \mathrm{cm}^{-2}$ air pump pressure using butane gas.

\subsection{Three-dimensional modeling}

The modeling was performed using the finite element method with cylindrical geometry domain, considering a three-dimensional mass transfer, the generalized equations of the second law of Fick (Bordin et al.2019) and Onsager (1945) equations. It was taken into account simplified considerations described by Bordin et al. (2019) and Angilelli et al. (2015), where the diffusion coefficient was considered constant, regardless of the position and the immersion time in the brine. The solute diffusion occurred under isothermal conditions $\left(20^{\circ} \mathrm{C}\right)$ and cheese contraction during salting was not considered. To evaluate the influence of the film formed on the Mozzarella cheese surface, in the static and dynamic salting systems, the Cauchy boundary condition was considered (Bona et al., 2007; Bordin et al., 2020) instead of Dirichlet boundary conditions, in which the concentrations obtained on the surface of the cheese immediately after dipping are the same as those of brine (Chung, 1978). The finite element formulation followed the procedures established by Cremasco et al. (2019) and Angilelli et al. (2015).
From these considerations, the respective concentrations of the $\mathrm{NaCl}$ and $\mathrm{KCl}$ solutes were represented by $\mathrm{C}_{1}(\mathrm{x}, \mathrm{y}, \mathrm{z}, \mathrm{t})$ and $\mathrm{C}_{2}(\mathrm{x}, \mathrm{y}, \mathrm{z}, \mathrm{t})$ at a given point $\mathrm{P}(\mathrm{x}, \mathrm{y}, \mathrm{z}) \in \Omega$ and at time $\mathrm{t}$, that can be solved by Onsager's (1945) equations, (Equation 1), Cauchy boundary conditions (Equations 2 and 3) and Biot number (Equation 4), presented in the Appendix A.

\subsection{Finite element method simulation}

The simulation was performed using COMSOL Multiphysics ${ }^{\circ}$ software version 5.2 (COMSOL, Inc., Burlington, MA) and the standard "Transport of Diluted Species (tds)" physical interface. The parameters used in the simulation were the main and cross diffusion coefficients, mass Biot number and the relationship between the mass transfer coefficient and the mass conductivity $\left(\mathrm{h}_{\mathrm{m}} / \lambda_{\mathrm{m}}\right)$ that were adjusted using the super modified simplex method coupled to the desirability functions, using an algorithm originally developed by Harrington (1965) and further enhanced by Derringer \& Suich (1980) (Bona et al., 2000). Figure 1 presents the solid generated automatically by the software, showing part of the extremely fine mesh used and the equidistant points chosen for the study of $\mathrm{Na}^{+}$and $\mathrm{K}^{+}$diffusion on the surface film formed in the Mozzarella cheese.

\subsection{Self-Organizing Map (SOM)-type neural networks}

The neural network routine was applied according to the algorithm described by Haykin (2001) and processed by Matlab ${ }^{\circ}$ R2007b software. It was used the self-organizing map (SOM) proposed by Kohonen \& Maps (1995) to evaluate the influence and behavior of $\mathrm{NaCl}$ and $\mathrm{KCl}$ concentrations in Mozzarella cheese surface. The applied network presented a $6 \times 6$ hexagonal topology ( 36 neurons) chosen by preliminary tests, with 8000 training epochs, with learning rate training starting at 0.2 and

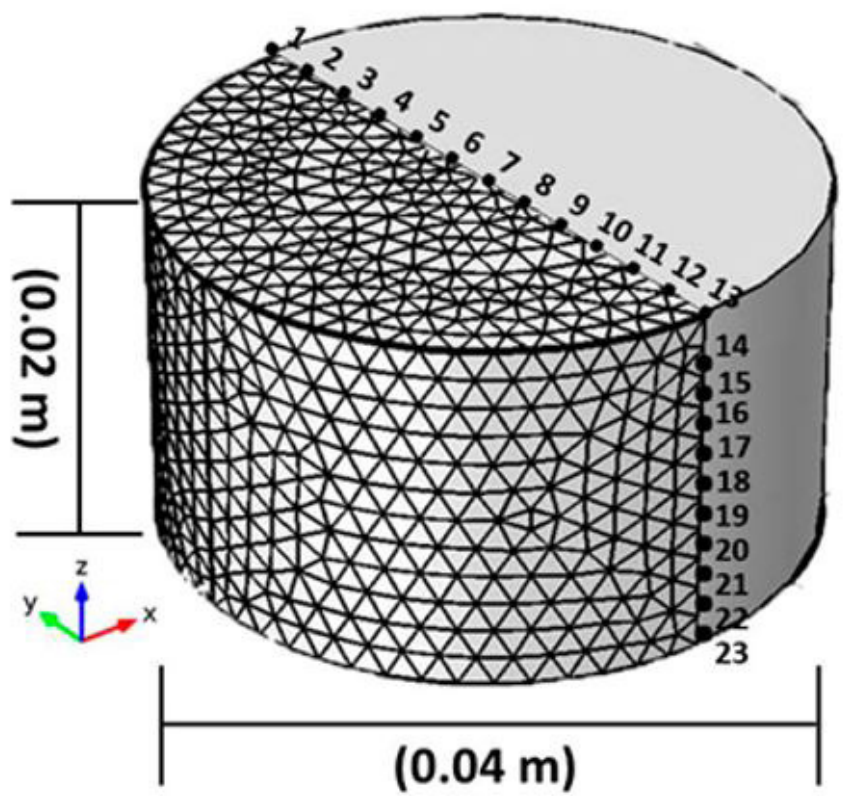

Figure 1. Solid automatically generated by the software and the positions used in the simulation. 
decaying exponentially with the training epochs to $6.71 \times 10^{-5}$, and the initial neighborhood relation was 3.5 decaying to 0.045 .

The topology choice used is important for the network's performance. If it is too small, the neighborhood relation between neurons is very close and the samples end up being classified into one group. On the other hand, if it is too large, several groups of specialized neurons are formed, and various neighborhood relationships are possible, consequently similar samples can be mistakenly classified into different groups (Cremasco et al., 2016). Thus, an adequate topology is directly related to the quality of the results, and the suitability depends, among other factors, on the number of samples, variables and the way they relate. The spreadsheets, with dimensions of $30 \times 24$ (Table $1 \mathrm{~S}$ and Table $2 \mathrm{~S}$ of Supplementary Material), contain the simulated concentrations in the points shown in Figure 1 (static and dynamic system) at the times of $0,0.25$, $0.75,1.0,2.5,6.5,7.5,9.5,10.5,11.5,17.5,19.0,29.0,36.0$ and 39 hours of salting, were provided to the SOM type neural network for classification.

\subsection{Computational processing}

It was used a computer Intel ${ }^{\oplus}$ Core $^{\mathrm{m}}$ i7-4790 CPU( 3.60 $\mathrm{GHz}, 32 \mathrm{~GB}$ RAM and $250 \mathrm{~GB}$ HDD.

\section{Results and discussion}

Table 1 shows the values of the Main and cross coefficients, mass transfer coefficient $\left(\mathrm{h}_{\mathrm{m}}\right)$ in the film, the relationship between the mass transfer coefficient $\left(\mathrm{h}_{\mathrm{m}} / \lambda_{\mathrm{m}}\right)$ and the Biot number determined by the finite element method using COMSOL Multiphysics ${ }^{\circledast}$ software, with the application of simplex optimization coupled with the desirability functions, during the diffusion process in the static and dynamic system (Bordin et al., 2020). All simulations were performed using a 3D geometry modeling, with time-dependent solver Backward Differentiation Formula (BDF) with extremely fine tetrahedral finite element mesh, and the continuum was divided into 44,275 tetrahedral elements with a convergence criterion of $10^{-4}$.

According to Table 1, the value of the main diffusion coefficient of sodium was higher than the potassium during diffusion of inorganic compounds in mozzarella cheese. The cross coefficients presented smaller values than the main ones, showing that the diffusion of the solutes in relation to their own flow is more important than the interference between them. The observed values of the main and crossed coefficients are the same for salting without and with agitation as they refer to the diffusion of ions inside the cheese.

The optimized $h_{m} / \lambda_{m}$ ratio showed a value of $1321.88 \mathrm{~m}^{-1}$ and a Biot number equal to 26.44, indicating the presence of a resistive barrier on the outer surface of the biosolid, because according to Borsato et al. (2012), the lower the number of Biot, the greater the influence of the layer in the flow of inorganic components at the interface. The number of Biot obtained for the static system indicates that the resistance to the dominant mass transfer is external (Bordin et al., 2019), and the values obtained for the Biot number and $\mathrm{h}_{\mathrm{m}} / \lambda_{\mathrm{m}}$ in the dynamic system indicate that the resistive barrier remains 3 times smaller when compared to diffusion in the static system. The film coefficient $\left(\mathrm{h}_{\mathrm{m}}\right)$ observed in Table 1 has a higher value for the dynamic system, indicating that the film is reduced, that is, there was no considerable influence in ion transfer during diffusion.

To assess whether the influence of the film depends on the position on the surface of the cheese, the concentrations of inorganic ions, in the positions located on the surface of the mozzarella cheese (Figure 1) were simulated by the FEM, and the chosen diffusion times were used as input variables in SOM to obtain topological and weight maps (Table $1 \mathrm{~S}$ and $2 \mathrm{~S}$ ).

Figure 2 shows the topological maps, for the static and dynamic system in the different diffusion times for sodium in the $\mathrm{X}$ and $\mathrm{Z}$-axes (Figure $2 \mathrm{a}$ and $2 \mathrm{~b}$ ) and potassium in the $\mathrm{X}$ and $Z$-axes (Figure $2 \mathrm{c}$ and $2 \mathrm{~d}$ ). The letters $S$ and $D$ represent the static and dynamic systems, respectively. The numbers represent the salting times chosen for the analysis by Artificial Neural Networks (ANN) to evaluate the influence of the film during the diffusive process. The SOM network classifies the input data as clusters, which can be formed by one or more neurons (Cremasco et al., 2019). The groups definition is characterized by the presence of clusters between empty neurons. In this way, neighbouring neurons have the same similarity.

Naturally, in all cases the samples S0 and D0 were classified in the same group, since the initial concentrations are the same in both systems.

Analyzing the distribution map in detail, it is possible to notice that for $\mathrm{Na}^{+}$on the $\mathrm{X}$ axis, Figure $2 \mathrm{a}$, a group in the upper left region is formed mainly by samples from S0.25 to S.2.5 and

Table 1. Main and cross coefficients, Biot number, the relationship between the mass transfer coefficient and the mass conductivity of the diffusion experiment.

\begin{tabular}{|c|c|c|c|c|}
\hline & \multicolumn{2}{|c|}{ Static Brine } & \multicolumn{2}{|c|}{ Dinamic Brine } \\
\hline & $\mathrm{Na}^{+}$ & $\mathrm{K}^{+}$ & $\mathrm{Na}^{+}$ & $\mathrm{K}^{+}$ \\
\hline Main coeff. $\left(\mathrm{m}^{2} \mathrm{~s}^{-1}\right)$ & $1.12 \times 10^{-9}\left(\mathrm{D}_{11}\right)$ & $0.91 \times 10^{-9}\left(D_{22}\right)$ & $1.12 \times 10^{-9}\left(\mathrm{D}_{11}\right)$ & $0.91 \times 10^{-9}\left(\mathrm{D}_{22}\right)$ \\
\hline Cross coeff. $\left(\mathrm{m}^{2} \mathrm{~s}^{-1}\right)$ & $1.70 \times 10^{-10}\left(D_{12}\right)$ & $1.69 \times 10^{-10}\left(\mathrm{D}_{21}\right)$ & $1.70 \times 10^{-10}\left(\mathrm{D}_{12}\right)$ & $1.69 \times 10^{-10}\left(\mathrm{D}_{21}\right)$ \\
\hline $\mathrm{h}_{\mathrm{m}}(\mathrm{m} / \mathrm{s})$ & $1.48 \times 10^{-6}$ & $1.20 \times 10^{-6}$ & $4.48 \times 10^{-6}$ & $3.64 \times 10^{-6}$ \\
\hline $\mathrm{h}_{\mathrm{m}} / \lambda_{\mathrm{m}}\left(\mathrm{m}^{-1}\right)$ & \multicolumn{2}{|c|}{1321.88} & \multicolumn{2}{|c|}{4000} \\
\hline Biot $^{*}$ & \multicolumn{2}{|c|}{26.44} & \multicolumn{2}{|c|}{80} \\
\hline
\end{tabular}

${ }^{*}$ Biot number calculated with respect to the $\mathrm{X}$-axis. 

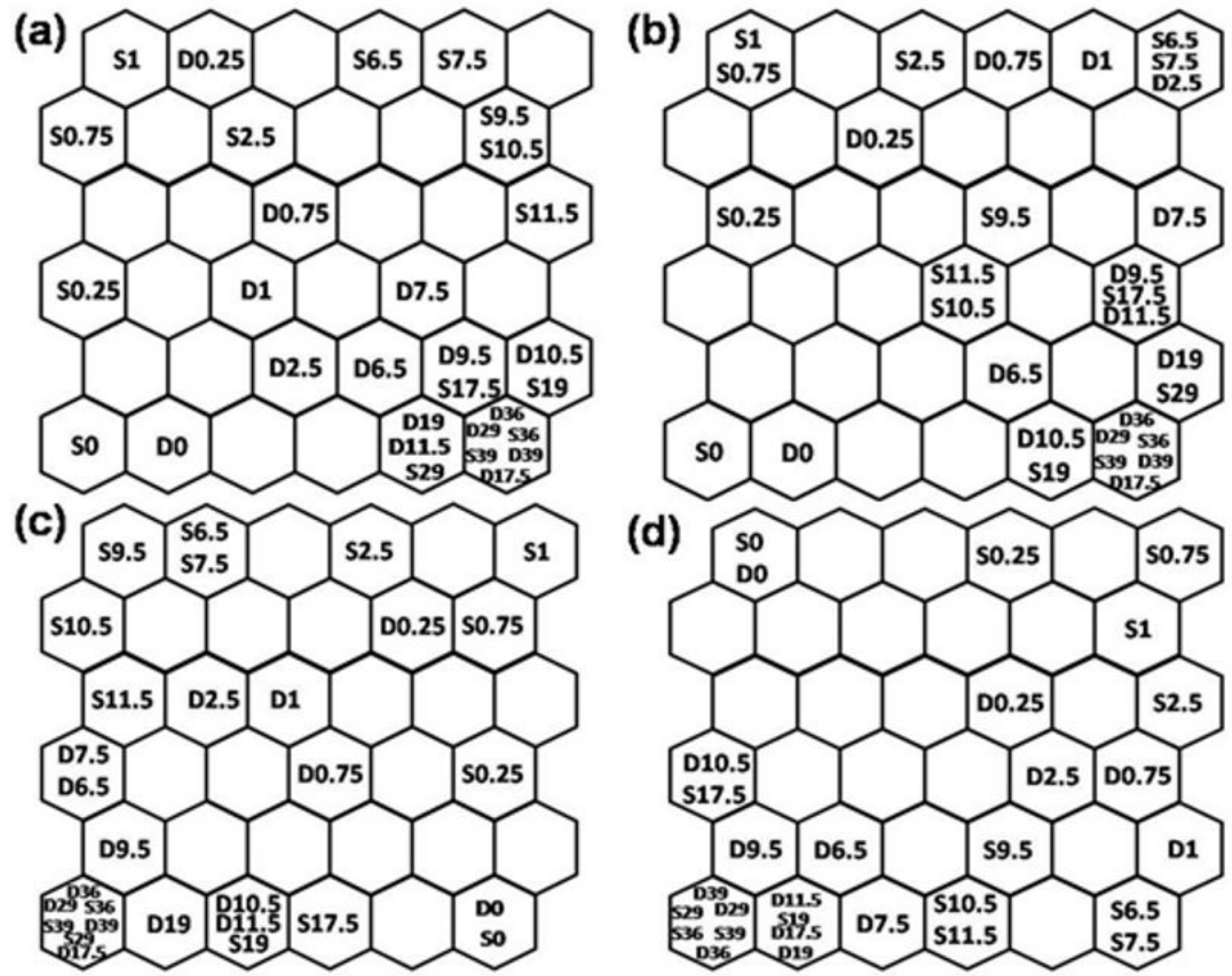

Figure 2. Topological maps for the diffusion of $\mathrm{Na}^{+}$and $\mathrm{K}^{+}$on the $\mathrm{X}$ and $\mathrm{Z}$-axis.

D0.25 to D1. This makes sense since longer times in the static system are needed to achieve concentrations similar to the agitated system with shorter times. A second group, upper right region, is formed by samples S6.5 to S11.5, indicating that the concentration gradient at these times is different from any time in the agitated system. Furthermore, a third group is observed in the lower right region, formed by samples S17.5 to S39 and D2.5 to D39, indicating that the sample D2.5 already has a similar concentration to the sample $S 17.5$, presenting again how much faster is the diffusion in the agitated system.

For $\mathrm{Na}^{+}$on the $\mathrm{Z}$ axis, Figure $2 \mathrm{~b}$, the position of samples S0.25 to S1 is different from the others, that is, at no time in the stirred system, even for the initial times, the concentrations were as low as these. Two large groups can be identified, the first formed by samples S2.5 to S7.5 and D0.25 to D2.5 and the second formed by samples S9.5 to S39 and D6.5 to D39. In Figure 2a, samples S17.5 and D2.5 have the shortest salting times in the group for both systems. In Figure $2 \mathrm{~b}$ are the samples S9.5 and D6.5, showing an expressive smaller disparity in relation to the times. It means that on the $\mathrm{Z}$ axis takes less time for the samples, in the static system, to reach the concentrations of the agitated system. This behavior can be explained by the solid geometry, since the surface on the $\mathrm{Z}$ axis is curved and naturally is subject to a greater number of collisions with the ions, making diffusion on the surface of the $\mathrm{Z}$ axis faster than on the $\mathrm{X}$ axis.

In Figures $2 \mathrm{c}$ and $2 \mathrm{~d}$, referring to the diffusion of $\mathrm{K}^{+}$on the $\mathrm{X}$ and $\mathrm{Z}$ axes, there are the same relations described above, but less accentuated than to sodium. The analysis of neighboring neurons comparing samples $\mathrm{S}$ and $\mathrm{D}$ at different times, also indicates that diffusion occurs slightly faster on the $\mathrm{Z}$ axis.

Figures 3, 4, 5 and 6 illustrate the weight maps, superimposed on the topological map, in the positions chosen on the $\mathrm{X}$ and $\mathrm{Z}$-axis (Figure 1). In the weight maps, the input variables are indicated by tone scales. The variables in same tone region present the same weight, that is, the same similarity. The clearest region has a greater weight value. It is possible to observe that there was a segmentation of the diffusion times of inorganic ions in mozzarella cheese in each studied position. 
The time distribution presented in the weight maps for position 1 is similar to the distribution observed for position 13, for both ions (Figures 3 and 5), which means that the ions enter in a similar way at points that are equidistant to the center of the biosolid surface. This analysis can be applied to the other weight maps presented.
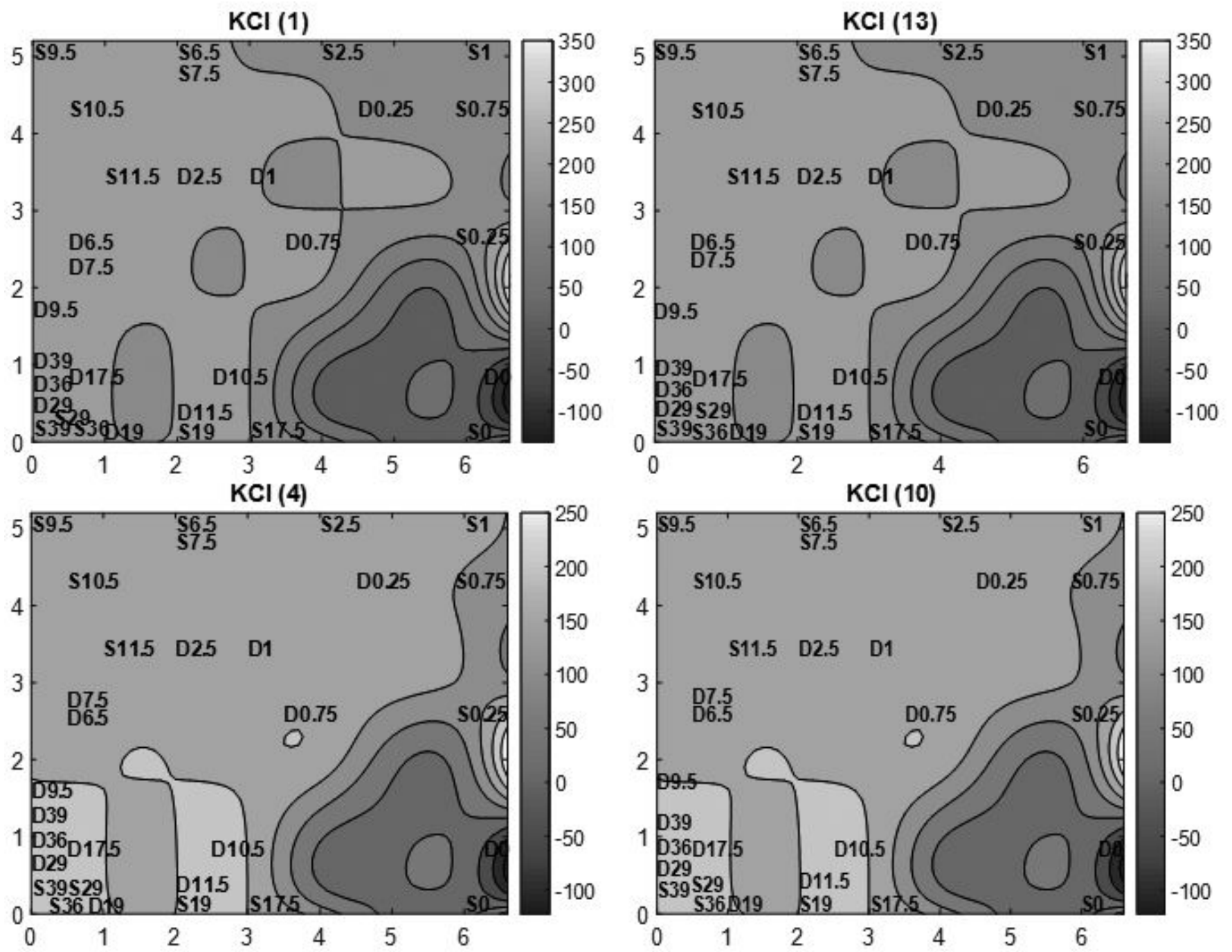

$\mathrm{KCl}(6)$
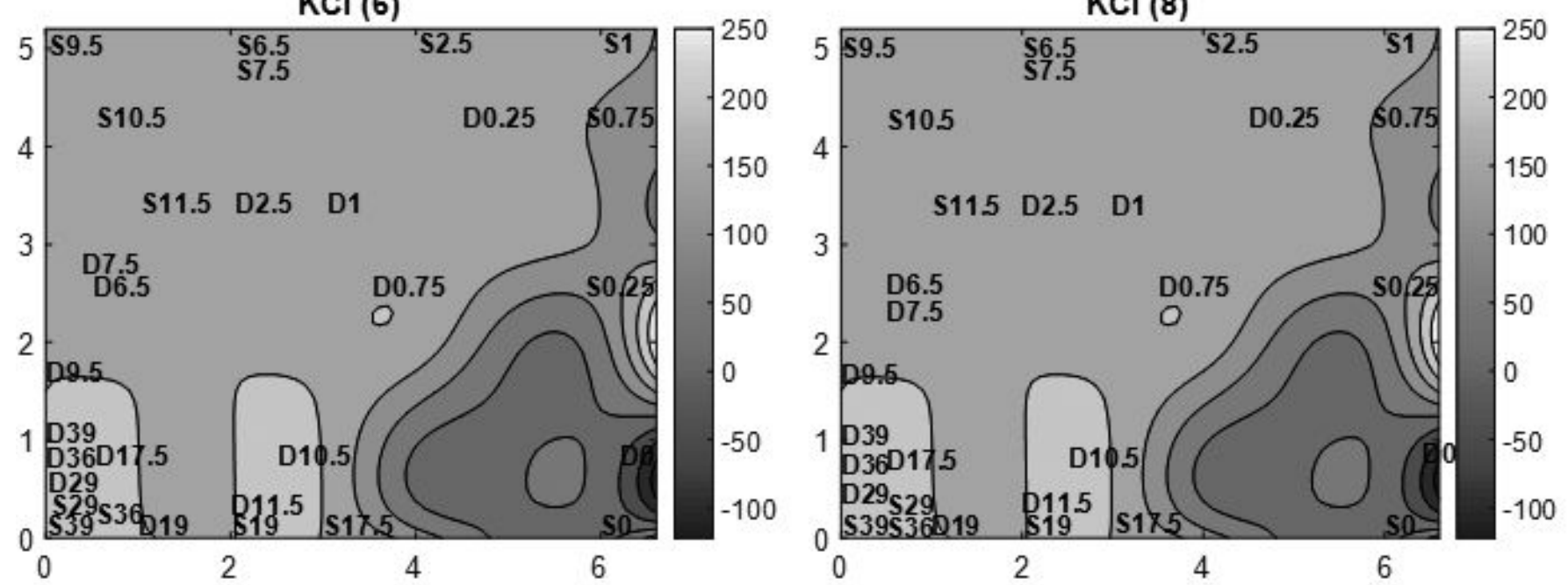

Figure 3. Weight maps of $\mathrm{K}^{+}$diffusion on the biosolid surface for the $\mathrm{X}$-axis in static and dynamic system. 
Among the positions studied, both on the $\mathrm{X}$-axis and on the Z-axis, it was observed that positions 1, 13 and 23 presented higher weights, at all times for the diffusion of both ions. The biosolid has cylindrical shape and these positions are located on the edges of the cheese (Figure 1), so that the diffusion takes place faster. It is suggested, therefore, that the film layer formed is thinner at the edges and thicker at the central outer part of the biosolid. In the other positions, in both processes, the times lower than $1 \mathrm{~h}$ of salting are in regions of lower weights, indicating that below this time the entry of ions on the surface is not yet relevant to the diffusion process.
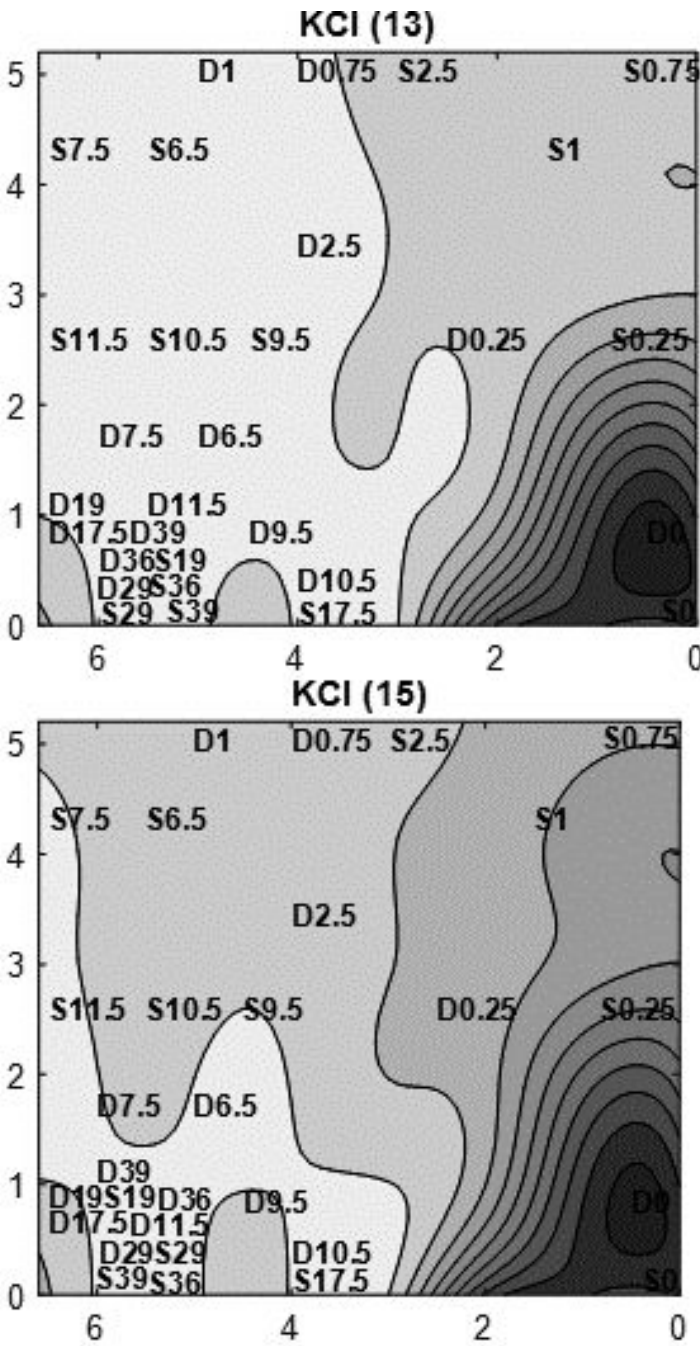

$\mathrm{KCl}(19)$

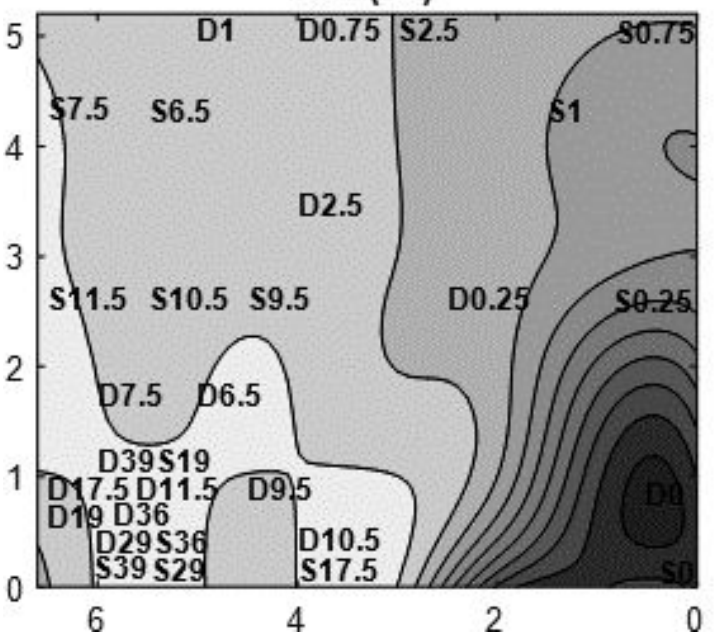

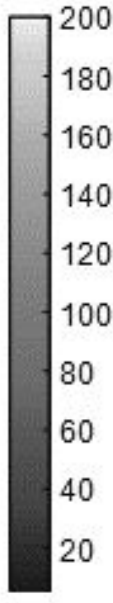
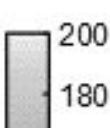

160

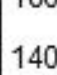

120

100

80

60

40 20
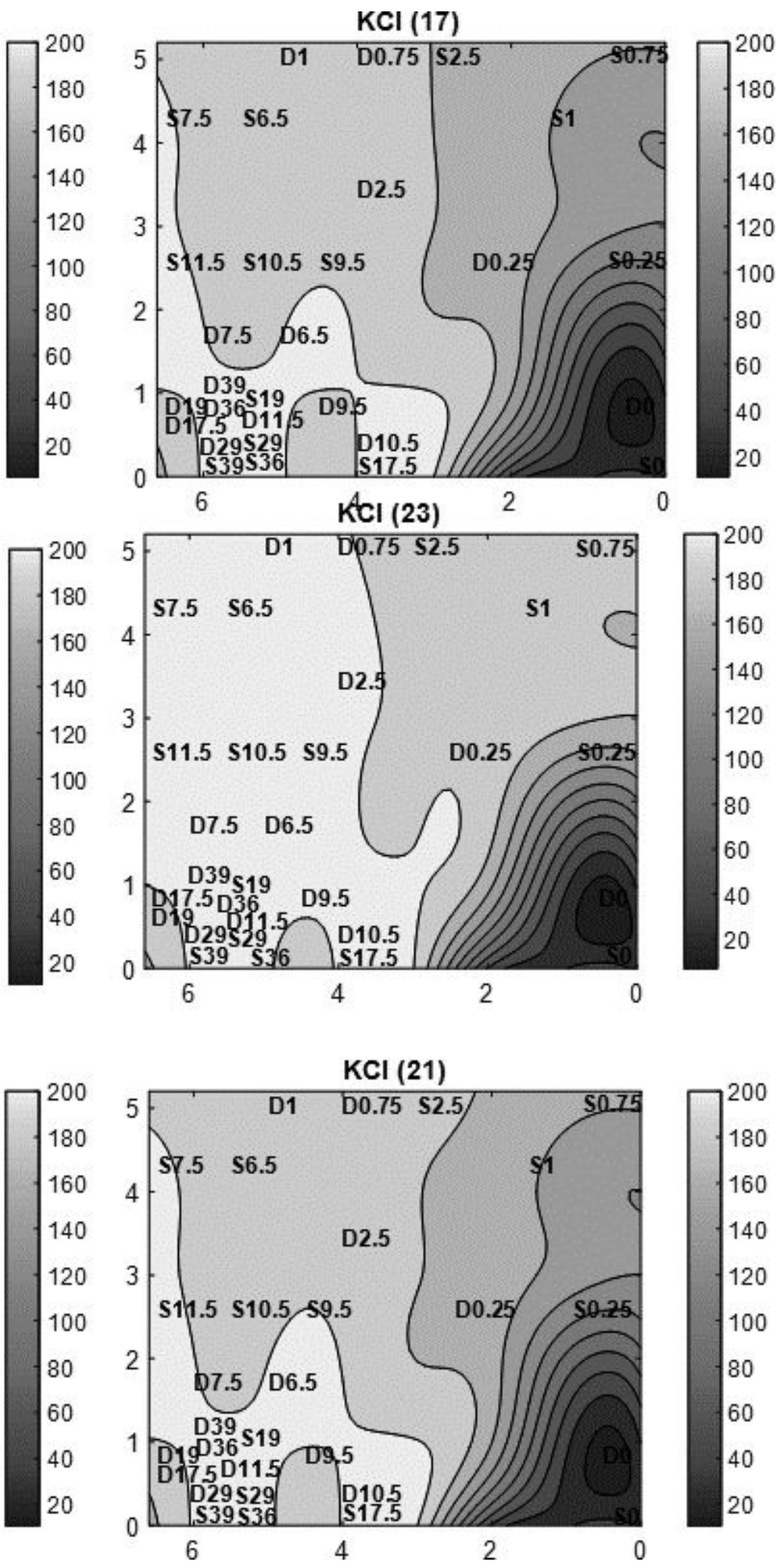

Figure 4. Weight maps of $\mathrm{K}^{+}$diffusion on the biosolid surface for the $\mathrm{Z}$-axis in static and dynamic system. 
The weight maps (Figure 3 ) for the diffusion of $\mathrm{KCl}$ on the $\mathrm{X}$-axis, showed that the times of $9.5 \mathrm{~h}, 10.5 \mathrm{~h}, 11.5 \mathrm{~h}, 17.5 \mathrm{~h}$ for the dynamic system, and $19 \mathrm{~h}, 29 \mathrm{~h}, 36 \mathrm{~h}, 39 \mathrm{~h}$ for static and dynamic systems showed the same weights in positions from 4 to 10 , indicating a homogeneous distribution of this ion on the
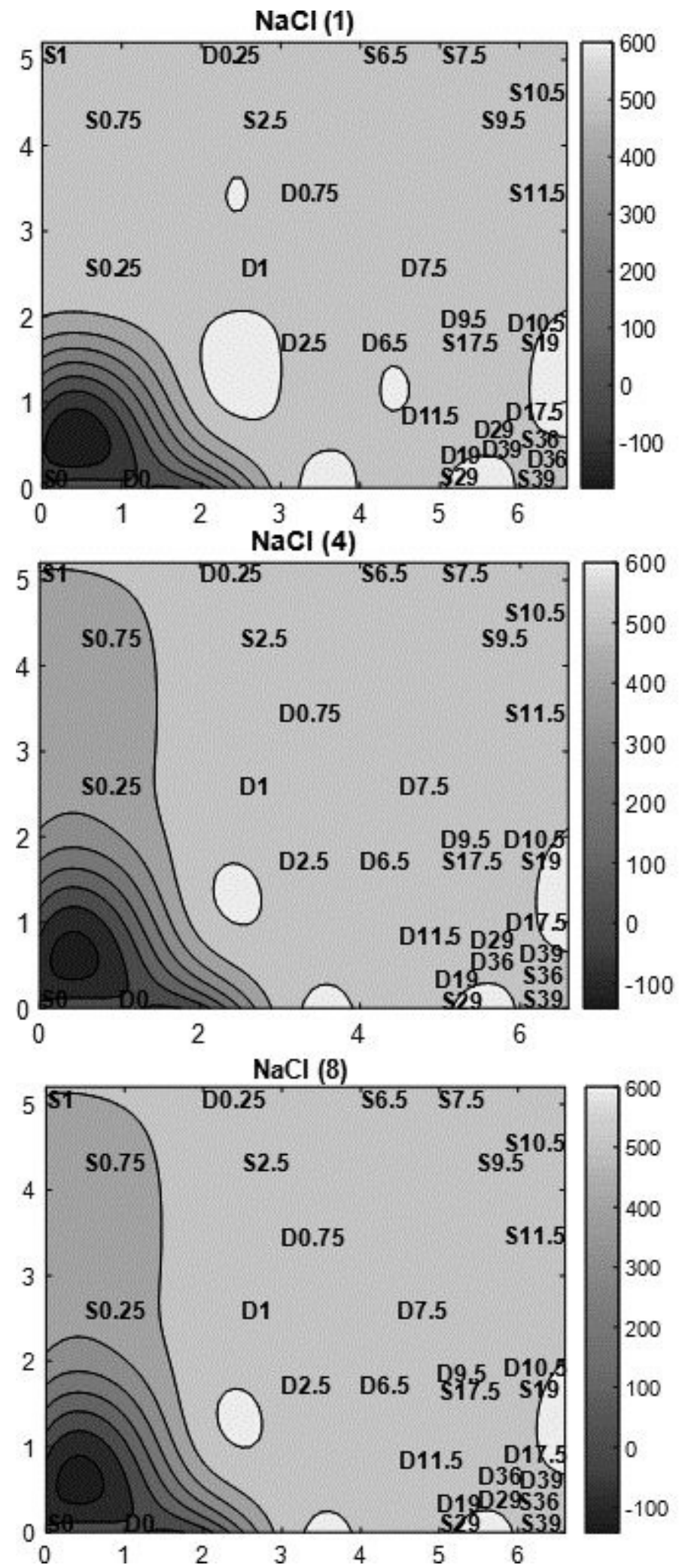

surface of the biosolid. Through the weight maps it was possible to observe that the highest $\mathrm{K}^{+}$levels were reached from $9.5 \mathrm{~h}$ and $19 \mathrm{~h}$ for the dynamic (D) and static (S) systems respectively, except for positions 1 and 13. In shorter diffusion times, only $75 \%$ of the total ions contained in the brine reach the interface.
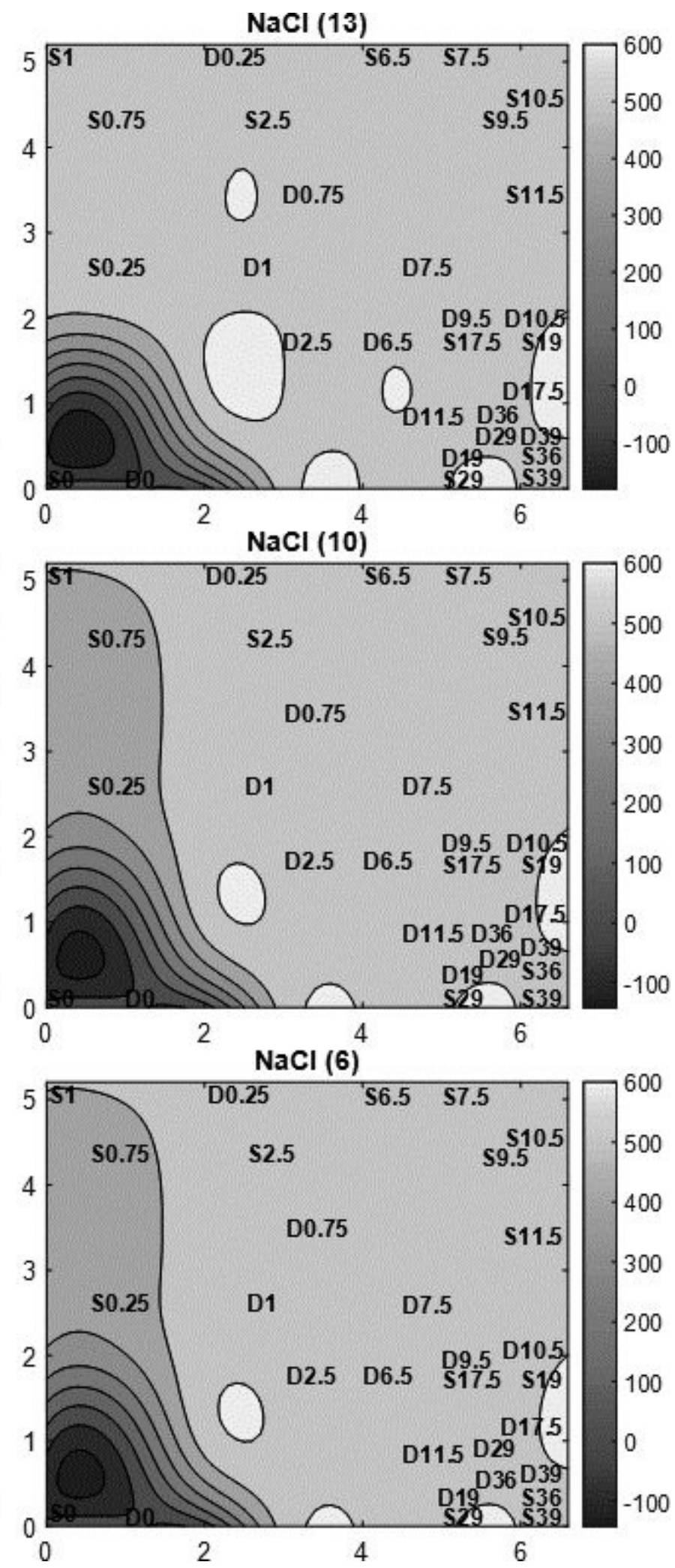

Figure 5. Weight maps of $\mathrm{Na}^{+}$diffusion on the biosolid surface for the $\mathrm{X}$-axis in static and dynamic system. 
Figure 4 shows the weight maps, containing mirrored positions for potassium diffusion on the Z-axis. In the same way that occurs on the $\mathrm{X}$-axis, it is noted that the positions 13 and 23, 15 and 21, 17 and 19 present similar profiles of distribution. The equalization of the $\mathrm{K}^{+}$ions occurred in 6.5 hours for the dynamic system, and in 7.5 hours for the static system in all positions, except those at 13 and 23. From these times, all the others are in the region of the map with the highest weight.

Figures 5 and 6 show the weight maps for the diffusion of $\mathrm{Na}^{+}$ions on the $\mathrm{X}$ and $\mathrm{Z}$-axis, respectively. The times lower than
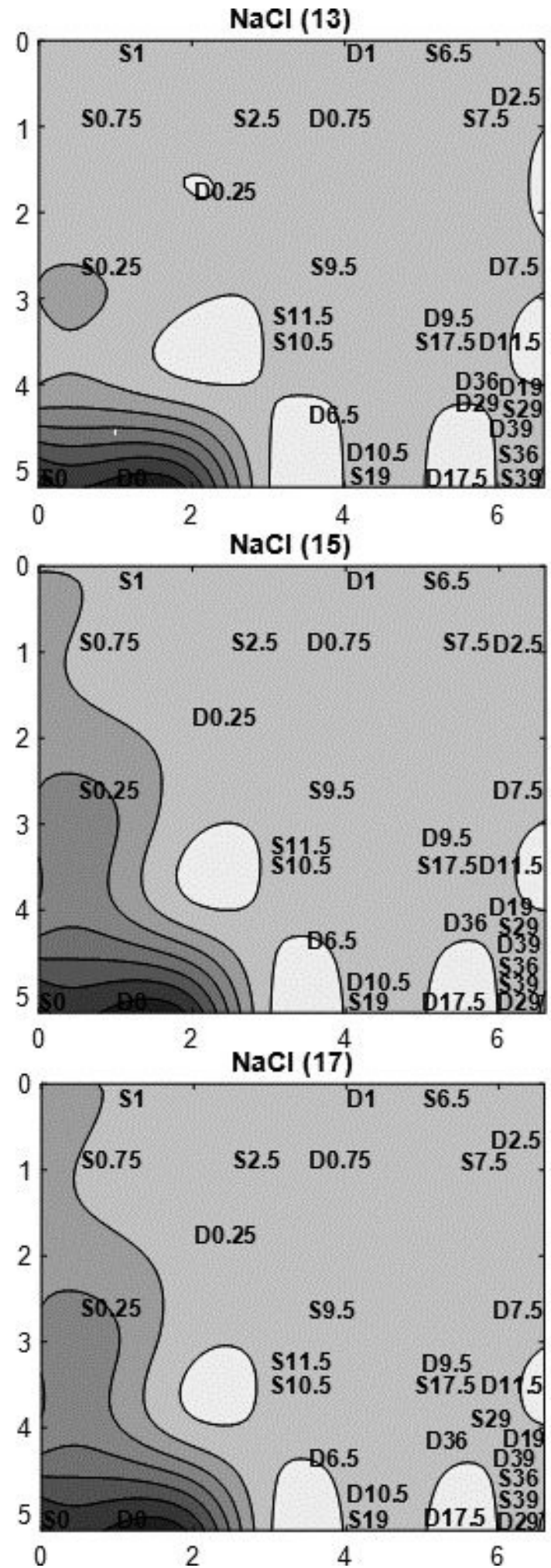
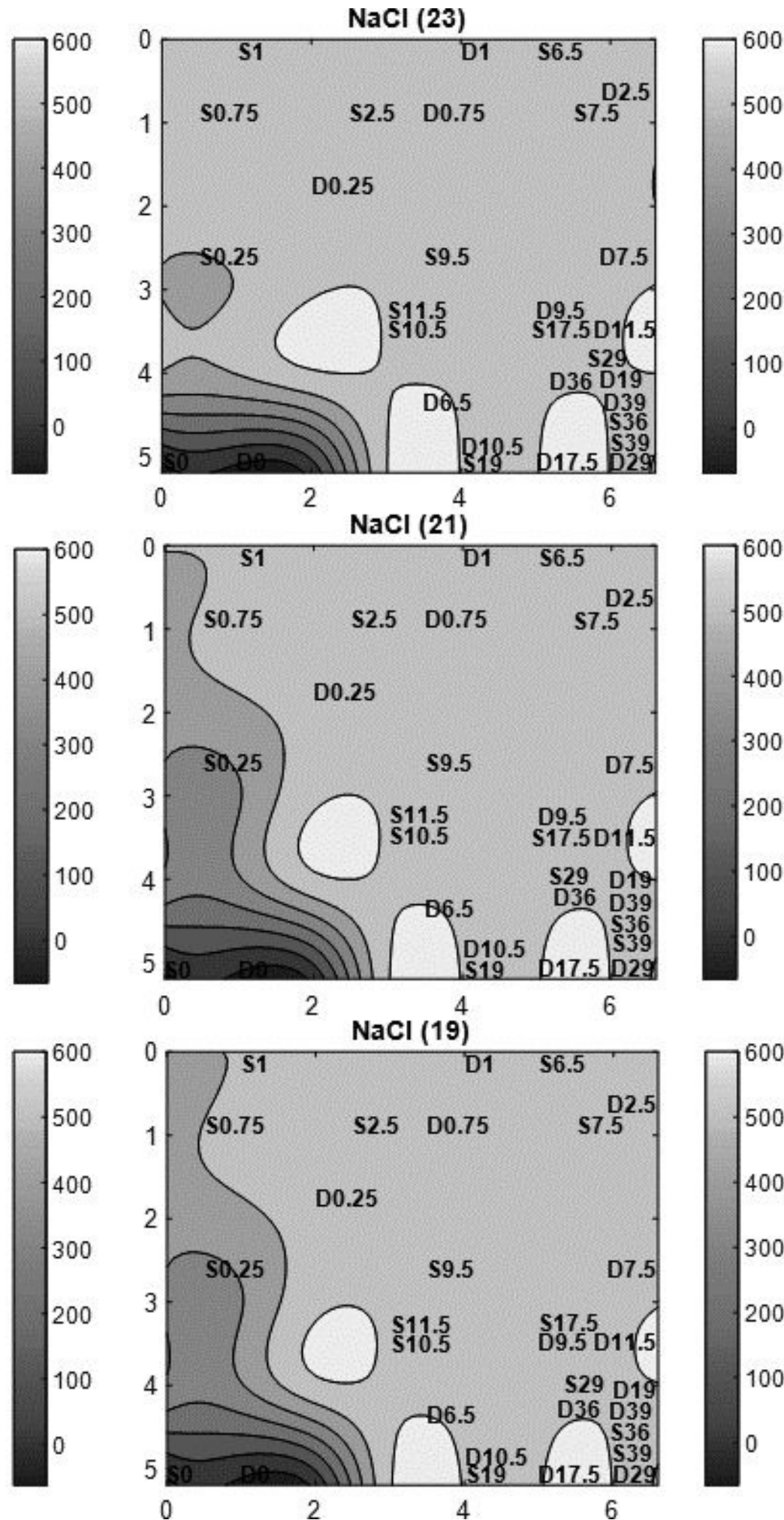

Figure 6. Weight maps of $\mathrm{Na}^{+}$diffusion on the biosolid surface for the Z-axis in static and dynamic system. 
$1 \mathrm{~h}$ of salting are located in regions of lower weights for the static system (S), which was not observed for the dynamic system (D), agreeing with the Biot number equal to 26.44 (Table 1) obtained for static brine. This number indicates the presence of a resistive barrier on the outer surface of the biosolid, with a greater influence of the layer in the flow of inorganic components at the interface (Cremasco et al., 2019). In the longer salting times, in both processes, the same weight was found, that is, the highest sodium levels on the surface of the Mozzarella cheese were achieved.

\section{Conclusions}

The application of artificial neural networks of the type self-organizing maps proved to be an efficient tool and easy to visualize, to evaluate the behavior of the film formed on the surface of the cheese during the diffusion process by immersion in aqueous solution, showing that this phenomenon influences the mass transfer and the salting time of the mozzarella cheese. The weight maps of the variables, superimposed on the topological maps, allowed to evaluate that the ions diffusion is hampered by the film formed at the biosolid/solution interface, being minimized with the stirring of the brine.

\section{References}

Albarracín, W., Sánchez, I. C., Grau, R., \& Barat, J. M. (2011). Salt in food processing; usage and reduction: a review. International Journal of Food Science \& Technology, 46(7), 1329-1336. http:// dx.doi.org/10.1111/j.1365-2621.2010.02492.x.

Angilelli, K. G., Orives, J. R., da Silva, H. C., Coppo, R. L., Moreira, I., \& Borsato, D. (2015). Multicomponent diffusion during osmotic dehydration process in melon pieces: influence of film coefficient. Journal of Food Processing and Preservation, 39(4), 329-337. http:// dx.doi.org/10.1111/jfpp.12236.

Association of Official Analytical Chemists - AOAC. (1994). Official methods of analysis of the Association of the Official Analysis Chemists (15th ed.). Washington: AOAC.

Bittar, R. D., Alves, S. M. F., \& Melo, F. R. (2018). Estimation of physical and chemical soil properties by artificial neural networks. Revista Caatinga, 31(3), 704-712. http://dx.doi.org/10.1590/198321252018v31n320rc.

Bona, E., Borsato, D., Silva, R. S. S. F., \& Herrera, R. P. (2000). Software for optimization using the sequential simplex method. Acta Scientiarum, 22, 1201-1206.

Bona, E., Carneiro, R. L., Borsato, D., Silva, R. S., Fidelis, D. A. S., \& Silva, L. H. M. (2007). Simulation of $\mathrm{NaCl}$ and $\mathrm{KCl}$ mass transfer during salting of Prato cheese in brine with agitation: a numerical solution. Brazilian Journal of Chemical Engineering, 24(3), 337-349. http://dx.doi.org/10.1590/S0104-66322007000300004.

Bordin, M. S. P., Borsato, D., Cremasco, H., Galvan, D., Silva, L. R. C., Romagnoli, É. S., \& Angilelli, K. G. (2019). Mathematical modeling of multicomponent $\mathrm{NaCl}$ and $\mathrm{KCl}$ diffusion process during the salting of pre-cooked champignon mushrooms. Food Chemistry, 273, 99-105. http://dx.doi.org/10.1016/j.foodchem.2018.01.188. PMid:30292382.

Bordin, M., Cremasco, H., Galvan, D., Clemente, M. A. J., Bona, E., Mantovanic, A. C. G., \& Borsato, D. (2020). Simultaneous transfer of $\mathrm{Na}+\mathrm{K}+$, and $\mathrm{Fe} 2+$ ions during salting of precooked mushroom (Agaricus bisporus): mathematical modeling, optimization, and experimental validation. Journal of the Brazilian Chemical Society, 31(6), 1101-1109. http://dx.doi.org/10.21577/0103-5053.20190275.
Borsato, D., Moreira, M. B., Moreira, I., Pina, M. V. R., Silva, R. S., \& Bona, E. (2012). Saline distribution during multicomponent salting in pre-cooked quail eggs. Food Science and Technology, 32(2), 281288. http://dx.doi.org/10.1590/S0101-20612012005000060.

Borsato, D., Pina, M. V. R., Spacino, K. R., Scholz, M. B. S., \& Androcioli Filho, A. (2011). Application of artificial neural networks in the geographical identification of coffee samples. European Food Research and Technology, 233(3), 533-543. http://dx.doi.org/10.1007/ s00217-011-1548-z.

Chung, T. J. (1978). Finite element analysis in fluid dynamics (NASA STI/Recon Technical Report A). New York: McGraw-Hill.

Cremasco, H., Borsato, D., Angilelli, K. G., Galão, O. F., Bona, E., \& Valle, M. E. (2016). Application of self organising maps towards segmentation of soybean samples by determination of inorganic compounds content. Journal of the Science of Food and Agriculture, 96(1), 306-310. http://dx.doi.org/10.1002/jsfa.7094. PMid:25641560.

Cremasco, H., Galvan, D., Angilelli, K. G., Borsato, D., \& Oliveira, A. G. (2019). Influence of film coefficient during multicomponent diffusion $-\mathrm{KCl} / \mathrm{NaCl}$ in biosolid for static and agitated system using 3D computational simulation. Food Science and Technology, 39(Suppl. 1), 173-181. http://dx.doi.org/10.1590/fst.40917.

Derringer, G., \& Suich, R. (1980). Simultaneous optimization of several response variables. Journal of Quality Technology, 12(4), 214-219. http://dx.doi.org/10.1080/00224065.1980.11980968.

Furtado, M. M. (1991). A arte e a ciência do queijo. São Paulo: Globo.

Gómez Salazar, J. A., Clemente Polo, G., \& Sanjuán Pelliccer, N. (2015). Review of mathematical models to describe the food salting process. Dyna, 82(190), 23-30. http://dx.doi.org/10.15446/dyna.v82n190.42016.

Guinee, T. P. (2004). Salting and the role of salt in cheese. International Journal of Dairy Technology, 57(2-3), 99-109. http://dx.doi. org/10.1111/j.1471-0307.2004.00145.x.

Harrington, E. C. (1965). The desirability function. Industrial Quality Control, 21(10), 494-498.

Haykin, S. (2001). Neural networks: a comprehensive foundation. Englewood Cliffs: Prentice-Hall.

Horita, C. N., Messias, V. C., Morgano, M. A., Hayakawa, F. M., \& Pollonio, M. A. R. (2014). Textural, microstructural and sensory properties of reduced sodium frankfurter sausages containing mechanically deboned poultry meat and blends of chloride salts. Food Research International, 66, 29-35. http://dx.doi.org/10.1016/j. foodres.2014.09.002.

Kohonen, T., \& Maps, S.-O. (1995). Springer Series in Information Sciences (Vol. 30). Berlin: Springer.

Kosikowski, F. (1978). Cheese and fermented milk foods. New York: FV Kosikowski and Associates.

Lai, W., Wang, H., Wang, C., Zhang, J., \& Zhao, Y. (2017). Waterlogging risk assessment based on self-organizing map (SOM) artificial neural networks: a case study of an urban storm in Beijing. Journal of Mountain Science, 14(5), 898-905. http://dx.doi.org/10.1007/ s11629-016-4035-y.

Lemes, M. R., \& Dal Pino, A. (2011). Periodic table of the elements in the perspective of artificial neural networks. Journal of Chemical Education, 88(11), 1511-1514. http://dx.doi.org/10.1021/ed100779v.

Maddah, H., Aghayari, R., Ahmadi, M. H., Rahimzadeh, M., \& Ghasemi, N. (2018). Prediction and modeling of MWCNT/Carbon (60/40)/ SAE $10 \mathrm{~W}$ 40/SAE $85 \mathrm{~W}$ 90(50/50) nanofluid viscosity using artificial neural network (ANN) and self-organizing map (SOM). Journal of Thermal Analysis and Calorimetry, 134(3), 2275-2286. http://dx.doi. org/10.1007/s10973-018-7827-1. 
Mattos, J. B., Cruz, M. J. M., De Paula, F. C. F., \& Sales, E. F. (2019). Mapeamento dos aspectos hidrogeoquímicos de águas subterrâneas a partir de estatística multivariada e redes neurais artificiais. Engenharia Sanitaria e Ambiental, 24(3), 501-514. http://dx.doi.org/10.1590/s1413-41522019178815.

Onsager, L. (1945). Theories and problems of liquid diffusion. Annals of the New York Academy of Sciences, 46(5), 241-265. http://dx.doi. org/10.1111/j.1749-6632.1945.tb36170.x. PMid:21024247.
Rodrigues, F. M., Rosenthal, A., Tiburski, J. H., \& Cruz, A. G. (2015). Alternatives to reduce sodium in processed foods and the potential of high pressure technology. Food Science and Technology (Campinas), 36(1), 1-8. http://dx.doi.org/10.1590/1678457X.6833.

Schwartzberg, H. G., \& Chao, R. Y. (1982). Solute diffusivities in leaching processes. Food Technology, 36(2), 73-86. 


\section{Supplementary Material}

Supplementary material accompanies this paper.

Table 1S. Salting time and axis positions studied for $\mathrm{Na}^{+}$diffusion in mozzarella cheese.

Table 2S. Salting time and axis positions studied for $\mathrm{K}^{+}$diffusion in mozzarella cheese.

This material is available as part of the online article from http://www.scielo.br/cta

Appendix A. Finite Element Formulation.

Onsager's equations

$\frac{\partial \mathrm{C}_{1}}{\partial \mathrm{t}}=\mathrm{D}_{11} \nabla^{2} \mathrm{C}_{1}+\mathrm{D}_{12} \nabla^{2} \mathrm{C}_{2}$ and $\frac{\partial \mathrm{C}_{2}}{\partial \mathrm{t}}=\mathrm{D}_{21} \nabla^{2} \mathrm{C}_{1}+\mathrm{D}_{22} \nabla^{2} \mathrm{C}_{2}$

Where $\mathrm{D}_{\mathrm{ii}}$ and $\mathrm{D}_{\mathrm{ij}}$ are the main and cross diffusion coefficients and $\nabla^{2}()=.\nabla . \nabla($.$) the Laplacian operator. The initial and boundary$ conditions used for the salting process, known as Cauchy boundary conditions, were described in mathematical terms by equations 2 and 3, respectively (Angilelli et al., 2015). The initial concentrations of $\mathrm{Na}^{+}$and $\mathrm{K}^{+}$in cheeses are represented by $\mathrm{C}_{1,0}$ and $\mathrm{C}_{2,0}$.

$\mathrm{C}_{1}(\mathrm{x}, \mathrm{y}, \mathrm{z}, 0)=\mathrm{C}_{1,0}$ and $\mathrm{C}_{2}(\mathrm{x}, \mathrm{y}, \mathrm{z}, 0)=\mathrm{C}_{2,0} \quad \mathrm{x}, \mathrm{y}, \mathrm{z} \in \Omega$

$\frac{\partial \mathrm{C}_{1}(\mathrm{R}, \mathrm{t})}{\partial \mathrm{n}}=\frac{\mathrm{h}_{\mathrm{m}}}{\lambda_{\mathrm{m}}}\left[\mathrm{C}_{1}-\mathrm{C}_{1, \mathrm{~s}}\right]$ and $\frac{\partial \mathrm{C}_{2}( \pm \mathrm{R}, \mathrm{t})}{\partial \mathrm{n}}=\frac{\mathrm{h}_{\mathrm{m}}}{\lambda_{\mathrm{m}}}\left[\mathrm{C}_{2}-\mathrm{C}_{2, \mathrm{~s}}\right] \quad \mathrm{x}, \mathrm{y}, \mathrm{z} \in \partial \Omega, \mathrm{t}>0$

Where $h_{m}\left(\mathrm{~m} \mathrm{~s}^{-1}\right)$ is the mass transfer coefficient of the solute in the formed film, $\lambda_{\mathrm{m}}\left(\mathrm{m}^{2} \mathrm{~s}^{-1}\right)$ the mass conductivity, $\partial \Omega$ the domain, $\partial / \partial \eta$ the operator of the normal derivative. The concentrations of the solutes present in the brine are represented by $\mathrm{C}_{1, \mathrm{~s}} \mathrm{e}$ $\mathrm{C}_{2, s}$. In equation 4 , the coefficients $\mathrm{h}_{\mathrm{m}}$ and $\lambda_{\mathrm{m}}$ are associated with the Biot number and $\mathrm{R}_{\mathrm{i}}$ is equal to the half-distance of the $\mathrm{X}$-axis (Figure 1) (Bordin et al., 2019; Angilelli et al., 2015).

$\mathrm{Bi}=\frac{\mathrm{h}_{\mathrm{m}} \mathrm{R}_{\mathrm{i}}}{\lambda_{\mathrm{m}}} \quad \mathrm{i}=1,2,3$ 


\section{ERRATUM: Application of artificial neural networks in the study of Mozzarella cheese salting}

Talita Fogaça de OLIVEIRA ${ }^{1}$, Marco Aurélio Jeanegitz CLEMENTE ${ }^{1}$, Diego GALVAN ${ }^{1}$, Gustavo FIX ${ }^{1}$, Ana Carolina Gomes MANTOVANI ${ }^{2}$, Ivanira MOREIRA ${ }^{1}$, Avacir Casanova ANDRELLO ${ }^{2}$, Karina Benassi ANGILELLI ${ }^{1}$, Dionísio BORSATO ${ }^{1 *}$

Due to authors honest mistake the article "Application of artificial neural networks in the study of Mozzarella cheese salting" (DOI https://doi.org/10.1590/fst.18320), published in Food Science and Technology, Campinas, 41(Suppl. 1): 375-385, June 2021, was published without the acknowledgements.

On page 383, after the Conclusions, it should be read:

\section{Acknowledgements}

National Council for Scientific and Technological Development - CNPq.

The authors apologize for the mistake. 